\title{
The potential of carabid beetles (Coleoptera) to reduce slug damage to oilseed rape in the laboratory
}

\author{
Frank OBERHOLZER, NAtalie ESCHER and Thomas FRANK* \\ Zoological Institute, University of Bern, Baltzerstrasse 6, CH-3012 Bern, Switzerland
}

\begin{abstract}
Key words. Carabidae, Deroceras laeve, Deroceras reticulatum, Poecilus cupreus, Pterostichus melanarius, predation, slugs
\end{abstract}
\begin{abstract}
Slugs are important pests of many agricultural crops, especially oilseed rape. The carabid beetles Pterostichus melanarius Illiger and Poecilus cupreus L. are among the most abundant large carabid beetles of European arable land and were therefore explored as potential slug antagonists. Damage to oilseed rape caused by the slugs Deroceras reticulatum Müller and $D$. laeve Müller in the presence or absence of $P$. melanarius and $P$. cupreus was observed in the laboratory. Whereas $P$. cupreus failed to reduce damage to oilseed rape by $D$. reticulatum, $P$. melanarius significantly reduced slug damage. However, $P$. melanarius was unable to protect oilseed rape from damage by $D$. laeve. This can be explained by the fact that $D$. laeve caused damage to oilseed rape below ground, where $P$. melanarius did not encounter the slugs. According to our laboratory experiments $P$. melanarius has the potential to reduce slug damage to oilseed rape by $D$. reticulatum.
\end{abstract}

\section{INTRODUCTION}

In temperate regions, some of the most widespread damage to agricultural and horticultural crops is due to slugs (South, 1992). Slug problems are mainly resolved by chemical molluscicides. Chemical molluscicides have been shown to affect non-target organisms, e.g. carabid beetles and earthworms (Bieri et al., 1989), and humid weather can decrease the effectiveness of molluscicides based on metaldehyde (Bailey \& Wedgwood, 1991). In addition, organic agriculture prohibits the use of chemical molluscicides. Thus, there is a need to search for alternative approaches to slug control in arable land.

For sustainable agricultural systems, regulation by predatory arthropods is considered to be crucial in preventing pest outbreaks. Polyphagous predatory carabid beetles are abundant on arable land, and are potentially important natural pest-control agents (Kromp, 1999). Several authors have found a negative correlation between the density of carabid beetles and aphids (Edwards et al., 1979; Sunderland et al., 1985; Chiverton, 1986; Basedow, 1990). Burn (1988) found higher numbers of slugs in field plots from which predators were excluded. This experiment indicated that predators may be capable of reducing slug population density. Several carabid beetles have been observed to feed on slugs (Symondson, in press), and some carabid beetles have considerable potential to decrease slug populations under controlled conditions (Symondson, 1993; Barker, 1991; Asteraki, 1993).

Pterostichus melanarius Illiger and Poecilus cupreus L. are some of the most abundant, large carabid beetles in European arable land (Thiele, 1977). Therefore they might be particularly effective control agents for slugs. $P$. melanarius was detected as a slug predator in the field, using immunological methods (Tod, 1973; Ayre \& Port,
1996; Symondson et al., 1996). P. melanarius seems to be a potentially important slug control agent as this beetle's spatial distribution was found to be significantly associated with slug distribution in winter wheat (Bohan et al., 2000). Moreover Symondson et al. (2002) observed a strong relationship between the crop weights of $P$. melanarius and slug densities over five years, indicating that slugs were a major part of the diet of the beetles. Much less information is available about predation by $P$. cupreus on slugs. A number of gut samples from $P$. cupreus gave positive reactions with anti-mollusc antiserum (Symondson, unpublished), suggesting that slugs were consumed by $P$. cupreus. In Germany and Switzerland, oilseed rape (Brassica napus L.) is sown in September and considered the most vulnerable crop to slug attack (Högger, 1995; Mesch, 1996). Deroceras reticulatum Müller is one of the most important slug pests occurring on Swiss arable land, and D. laeve Müller occasionally reaches fairly high densities in oilseed rape fields (Frank, 1998; Speiser, 1999).

The overall object of this study was to explore whether or not the presence of two common predacious carabids affects slug feeding on young oilseed rape in the laboratory. Specifically we examined whether: (1) P. melanarius and $P$. cupreus have the potential to protect oilseed rape from damage by $D$. reticulatum, (2) $P$. melanarius can protect oilseed rape from damage by both $D$. reticulatum and D. laeve.

\section{MATERIAL AND METHODS}

Experiment 1. Slug damage by Deroceras reticulatum to germinating oilseed rape in the presence of Pterostichus melanarius and Poecilus cupreus.

D. reticulatum were kept in plastic boxes of $19 \times 9 \times 7.5 \mathrm{~cm}$, filled with $3 \mathrm{~cm}$ depth of potting compost and fed on a diet of wheat flour. The slugs were kept in an environmental chamber

\footnotetext{
* Corresponding author. E-mail: thomas.frank@zos.unibe.ch
} 
with a temperature cycle of $15^{\circ} \mathrm{C}$ and $10^{\circ} \mathrm{C}$ at $12 \mathrm{~L}: 12 \mathrm{D}$. Slugs were classified into two groups weighing $17.3 \pm 8.0 \mathrm{mg}$ and $36.7 \pm 9.1 \mathrm{mg}$, respectively (mean $\pm \mathrm{SD} ; N=20$ ). Slugs of the lighter groups were raised in the laboratory from eggs, and the heavier slugs were collected in the garden of the Zoological Institute.

$P$. melanarius and $P$. cupreus were collected at the beginning of September 1999 over four days with pitfall traps (plastic cups, diameter $70 \mathrm{~mm}$, depth $70 \mathrm{~mm}$ ) that were emptied daily The beetles were kept in plastic boxes measuring $17 \times 12.5 \times 6$ $\mathrm{cm}$, with a piece of moist cotton, under the same temperature and light conditions as the slugs. They were fed on a diet of cat food. The beetles were starved 48 hours prior to the experiment.

In September 1999, twenty oilseed rape seeds (B. napus; cv. "Express") were sown at $1 \mathrm{~cm}$ depth in 60 plastic boxes of $30 \mathrm{x}$ $24.5 \times 8 \mathrm{~cm}$, filled with $3 \mathrm{~cm}$ of potting compost. The upper half of the inner wall was brushed with Antischneck-Gel ${ }^{\circledR}$ (Neudorff $\mathrm{GmbH}$, Emmerthal, Germany) to prevent the slugs from escaping. Each box was exposed to one of the following six treatments: 1) control, 2) 2 small and 2 large slugs (S), 3) $1 P$. melanarius (PM), 4) 1 P. cupreus (PC), 5) $\mathrm{S}+\mathrm{PM}, 6) \mathrm{S}+\mathrm{PC}$ Treatments 3 ) and 4) with beetles alone were used because there is no information available as to whether or not these carabid beetles have any impact on oilseed rape development. There were ten replicates of each treatment. The boxes were randomly arranged. The slugs and the carabids were put simultaneously into the boxes immediately after the seeds were sown. Seventeen days after sowing, before all oilseed rape plants in the slug treatments were damaged, the number of living plants in each box was recorded. A living plant was defined as being defoliated less than $75 \%$. Since there was not sufficient space in the environmental chamber we carried out the experiment in the laboratory at room temperature with natural daylight, accepting higher experimental temperature conditions compared to those in the field when oilseed rape is sown. To record the number of slugs that survived in the treatments $\mathrm{S}, \mathrm{S}+\mathrm{PM}$ and $\mathrm{S}+\mathrm{PC}$, the beetles and plants were removed and the compost of each box was transferred to a plastic box of $17 \times 12.5 \times 6 \mathrm{~cm}$ with five holes of about $3 \mathrm{~mm}$ diameter in the bottom. The boxes were covered with plastic lids and transferred to troughs of $60 \times 40 \times$ $11 \mathrm{~cm}$, where they were gradually flooded, allowing the extraction of slugs over six days (South, 1964). The boxes were examined daily and all recovered slugs removed.

The data for the number of living plants and recorded slugs were adjusted to a one-way ANOVA followed by Tukey's HSD-test to compare differences between the treatments.

Experiment 2a. Slug damage by Deroceras reticulatum to germinating oilseed rape in the presence of Pterostichus melanarius.

$D$. reticulatum used in this experiment originated from the Lonza laboratory (Visp, Switzerland). They were kept on moist blotting paper in plastic boxes $(33.5 \times 23 \times 3 \mathrm{~cm})$ and fed with flour and leaves of lettuce. The slugs were kept in an environmental chamber with a temperature cycle of $15^{\circ} \mathrm{C}$ and $10^{\circ} \mathrm{C}$ at $12 \mathrm{~L}: 12 \mathrm{D}$. Slugs were classified into two groups weighing 16.3 $\pm 5.3 \mathrm{mg}$ and $34.8 \pm 6.2 \mathrm{mg}$, respectively (mean $\pm \mathrm{SD} ; N=48$ for small and $N=16$ for large slugs).

$P$. melanarius were collected at the beginning of September 2000 in a field near Bern by pitfall trapping (plastic cups, diameter $70 \mathrm{~mm}$, depth $70 \mathrm{~mm}$ ) over several days. They were kept in the laboratory in plastic boxes $(34 \times 23 \times 9 \mathrm{~cm})$ with a piece of moist cotton wool and fed with a diet of cat food under the same environmental conditions as described above. The beetles were starved 48 hours prior to the experiment.
In September 2000, twenty oilseed rape seeds (Brassica napus; cv. "Express") were sown at $1 \mathrm{~cm}$ depth in 5 rows in 32 plastic boxes of $30 \times 24.5 \times 8 \mathrm{~cm}$, filled with $3 \mathrm{~cm}$ of potting compost. The upper half of the inner wall of each box was

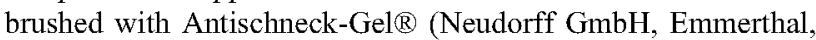
Germany) to prevent the slugs from escaping. Additionally, the top of each box was surrounded by a $3 \mathrm{~cm}$ wide barrier of aluminium foil to prevent the carabids from escaping. Each box had a piece of plastic pot for the slugs to hide. Each box was exposed to one of the following four treatments: 1) control, 2) 3 small and 1 large slug (DR), 3) 1 beetle (PM) and 4) DR + PM. There were eight replicates for each treatment. The weight of four slugs per box was $83.7 \pm 1.8 \mathrm{mg}$ (mean $\pm \mathrm{SD}$ ). The slugs and the carabids were put simultaneously into the boxes immediately after the seeds were sown. The boxes were randomly arranged and the experiment was carried out in the laboratory at room temperature with natural daylight. After the oilseed rape seedlings emerged the number of living plants was recorded every second day until day 17 after sowing, before all oilseed rape plants in the slug treatments were damaged.

To obtain a comprehensive overview over the time course of number of living oilseed rape plants, the area under the damage progress curve (AUDPC; Campbell \& Madden, 1990; Speiser, 1997) was analysed, using the formula

$$
\text { AUDPC }=\sum_{i}^{n-1}\left(\left(y_{i}+y_{i+1}\right) / 2\right)\left(t_{i+1}-t_{i}\right)
$$

where $y_{\mathrm{i}}$ is the number of living oilseed rape plants at the $i$-th measurement, $\mathrm{t}_{\mathrm{i}}$ is the time at the $i$-th measurement (in days) and $n$ is the number of measurements (six). To test for differences among the four treatments the AUDPC data were compared with one-way ANOVA followed by Tukey's HSD-test. As data were normally distributed untransformed values were used for statistical analysis.

Experiment 2b. Slug damage by Deroceras laeve to germinating oilseed rape in the presence of Pterostichus melanarius.

$D$. laeve used in this experiment were collected at the end of August 2001 in a wildflower area near Bern. They were kept in the laboratory as the slugs of experiment $2 \mathrm{a}$. Slugs were classified into two groups weighing $25.1 \pm 8.0 \mathrm{mg}$ and $7.0 \pm 2.1 \mathrm{mg}$, respectively (mean $\pm \mathrm{SD} ; N=48$ for large and $N=16$ for small slugs).

$P$. melanarius were from the same field as in experiment $2 \mathrm{a}$. They were kept and starved prior to the experiment as in experiment $2 \mathrm{a}$.

In September 2001, 32 plastic boxes of $30 \times 24.5 \times 8 \mathrm{~cm}$ were prepared in the same way as described in experiment $2 \mathrm{a}$. Each box was exposed to one of the following four treatments: 1) control, 2) 3 large and 1 small slug (DL), 3) 1 beetle (PM) and 4) DL + PM. There were eight replicates for each treatment. The weight of four slugs per box was $82.2 \pm 1.4 \mathrm{mg}$ (mean \pm SD) and adapted to the weight of $D$. reticulatum used in experiment 2a. The experiment was performed and statistically analysed analogous to experiment 2a. Additionally, the number of slugs that survived in the treatments DL and DL + PM was recorded as described in experiment 1 .

For the comparison of the numbers of survived slugs a MannWhitney $U$-test was calculated, because these data were not normally distributed.

\section{RESULTS}

Experiment 1 showed that in the treatment with slugs only, the number of living oilseed rape plants was significantly lower than in all other treatments except for slugs with $P$. cupreus (Fig. 1). Whereas P. cupreus did not affect the number of slugs recorded, $P$. melanarius 


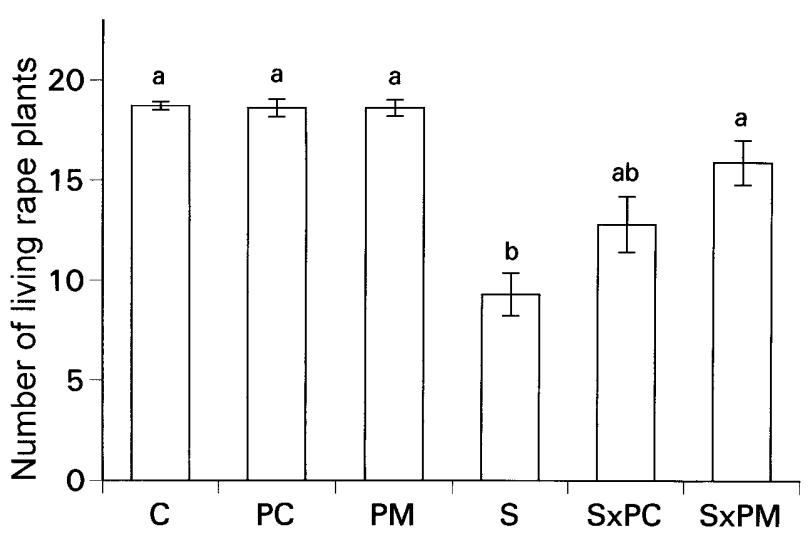

Fig. 1. Number of living oilseed rape plants in the different treatments (mean $\pm \mathrm{SE}$ ). Treatments sharing the same letter are not significantly different $(P>0.05$; Tukey's HSD-test; $N=$ $60) . \mathrm{C}=$ control, $\mathrm{PC}=P$. cupreus, $\mathrm{PM}=P$. melanarius, $\mathrm{S}=$ slug.

reduced slug numbers significantly when compared to the treatment slugs only $(P<0.05$; Tukey's HSD-test; $N=$ $30)$.

We carried out experiment $2 \mathrm{a}$ to verify the general effects found for $P$. melanarius in experiment 1 . The number of living oilseed rape plants in the treatment slugs only declined clearly from day 7 to day 17 after sowing, and was significantly lower than in the other treatments (Fig. 2). As in experiment 1, the presence of $P$. melanarius together with $D$. reticulatum significantly increased plant number compared to the treatment slugs only. However, the control contained significantly more plants than the treatment $P$. melanarius plus $D$. reticulatum.

In the treatments in experiment $2 \mathrm{~b}$ where $D$. laeve was present there was a dramatic decrease of oilseed rape before the plants emerged, indicating that seeds and young seedlings below ground were most vulnerable to slug attack. The number of plants in all treatments remained almost equal from day 7 to day 17 (Fig. 3). As

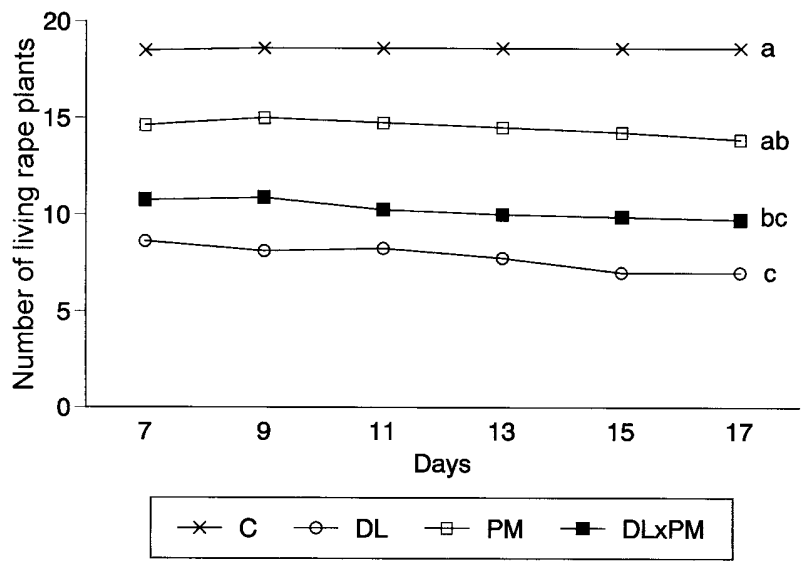

Fig. 3. Mean number of living oilsed rape plants between days 7 to 17 after sowing. Treatments sharing the same letter are not significantly different $(P>0.05$; standardised AUDPC; Tukey's HSD-test; $N=32$ ). $\mathrm{C}=$ control, $\mathrm{DL}=D$. laeve, $\mathrm{PM}=$ P. melanarius.

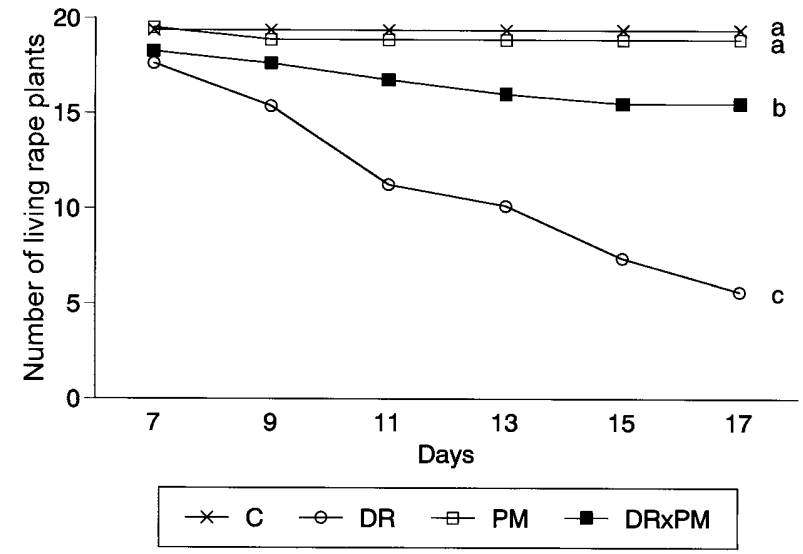

Fig. 2. Mean number of living oilseed rape plants between days 7 to 17 after sowing. Treatments sharing the same letter are not significantly different $(P>0.05$; standardised AUDPC; Tukey's HSD-test; $N=32$ ). $\mathrm{C}=$ control, $\mathrm{DR}=D$. reticulatum, $\mathrm{PM}=P$. melanarius .

in experiment $2 \mathrm{a}$, the control and the treatment with $P$. melanarius alone contained significantly more oilseed rape plants than the treatment where only slugs were present. The presence of $P$. melanarius together with $D$. laeve did not affect plant number when compared to the treatment slugs only. At the end of experiment $2 b$, significantly more slugs survived in the treatment slugs only compared to the treatment $P$. melanarius plus $D$. laeve ( $P$ $=0.003$; Mann-Whitney $U$-test; $N=16$ ).

\section{DISCUSSION}

Experiment 1 indicated that slug predation by $P$. melanarius took place. This is important regarding the debate on whether carabids are effective predators or mainly scavenge dead slugs (Symondson \& Liddell, 1993; Symondson et al., 1996). Slugs mainly defend themselves against predacious beetles by the production of a sticky mucus (Pakarinen, 1994), which makes slugs a difficult prey item (Rollo \& Wellington, 1979; Denny, 1989). It has been suggested that large carabids overcome this defence more easily than smaller ones (Mc Kemey et al., 2001). This was confirmed by our results, which showed that the larger $P$. melanarius (about $15 \mathrm{~mm}$ body size) effectively reduced damage to oilseed rape by the slug $D$. reticulatum. The smaller $P$. cupreus (about $11 \mathrm{~mm}$ body size), in contrast, hardly affected slug damage. Previously, $P$. melanarius was observed to kill more $D$. reticulatum compared to $P$. cupreus (Oberholzer \& Frank, 2003). The larger mandibles of $P$. melanarius may enable that beetle to attack slugs more successfully when compared with $P$. cupreus, because larger mandibles most likely agglutinate less with slug mucus than smaller ones. $P$. melanarius was shown to ingest more prey items than $P$. cupreus in the laboratory (Scherney, 1959) and thus might consume more slugs and protect oilseed rape more efficiently from slug feeding.

Experiment 2a substantiated the potential of $P$. melanarius to protect oilseed rape from damage by $D$. reticulatum. However, experiment $2 \mathrm{~b}$ revealed that $P$. 
melanarius was not able to protect oilseed rape from damage by $D$. laeve. $D$. reticulatum had no impact on the number of germinating oilseed rape seedlings below ground, proving that this slug reduced oilseed rape exclusively by epigeic feeding. In oilseed rape fields where $D$. reticulatum belongs to the most abundant slug pests damage to oilseed rape was also primarily caused by epigeic feeding (Friedli \& Frank, 1998). When slugs are on the surface they will often encounter $P$. melanarius and easily be overwhelmed by the beetle. In contrast, damage to oilseed rape by $D$. laeve seemed to have been almost exclusively caused by endogeic feeding, because in the treatments where $D$. laeve was present there was a dramatic decrease of oilseed rape before the plants emerged. This agrees with a previous laboratory study where $D$. laeve exclusively fed on oilseed rape below ground (Frank, 1998). Thus it appears that $P$. melanarius did not encounter $D$. laeve and hence was not able to kill it. But nevertheless, at the end of experiment $2 b$, significantly less $D$. laeve survived in the presence of $P$. melanarius compared to the treatment without the beetle, proving that $P$. melanarius significantly reduced slug numbers. However, slug predation by $P$. melanarius occurred only when the oilseed rape plants were already destroyed by $D$. laeve. This suggests that the beetle only encountered $D$. laeve when it began to leave the soil to feed on oilseed rape above ground, when young oilseed rape had attained a developmental stage at which it was no more at risk of D. laeve.

$P$. melanarius is in its peak period of activity-density when oilseed rape is being sown (from the end of August until mid-September), which makes this beetle an ideal candidate to protect young oilseed rape from slug pests. Activity-density of $P$. cupreus is already declining at that time (Frank, unpublished). A combined occurrence of both beetles may contribute to prevent outbreaks of the pest slug $D$. reticulatum by consuming its eggs and freshly hatched individuals, as was previously observed (Oberholzer \& Frank, 2003). However, the beetles appear to be insufficient in affecting population density of the soil dwelling $D$. laeve. However, it might be that the predatory larvae of $P$. melanarius, which spend most of the time in the soil (Traugott, 1998), may have an impact on the population size of $D$. laeve.

Slugs were shown to be an important prey for $P$. melanarius in the field (Symondson et al., 2002), which is a prerequisite for a high potential of that beetle to reduce slug populations. Although P. melanarius is a generalist predator, a reduction in slug population growth rate was observed in field areas with high densities of $P$. melanarius (Bohan et al., 2000), which further shows that slugs were a single important prey type for $P$. melanarius. The fact that one type of prey plays a significant role for a generalist predator may be common in agroecosystems, where food diversity for carabid predators appears to be scarce (Van Dijk, 1996). Generalist predators may have an advantage over specialists in agricultural landscapes, because they are able to retain moderate population sizes when the target prey densities are low by feeding on alternative prey (Murdoch et al., 1985).

High beetle densities are necessary for an effective reduction of slug populations. Carabid abundance can be increased by the renunciation of insecticide application (Gese, 1974; Basedow et al., 1976), which is fulfilled by organic agriculture where particularly high carabid densities can be observed (Kromp, 1989; Pfiffner \& Niggli, 1996). Furthermore carabid density can be enhanced by reducing herbicide application thus increasing the growth of weeds, by intercropping herbs between crop rows (see references in Kromp, 1999), or by establishing ecological compensation areas adjoining arable crops (Lys \& Nentwig, 1992, 1994; Frank, 1997).

ACKNOWLEDGEMENTS. We wish to thank J.-P. Airoldi for statistical help. Special thanks to K. Christensen for providing slugs. M. Gygli provided the field in Belp, and H. Ramseier put a threshing machine at our disposal. N.E. was paid by the Swiss National Science Foundation (Project No. 3100-055482).

\section{REFERENCES}

Asteraki E.J. 1993: The potential of carabid beetles to control slugs in grass/clover swards. Entomophaga 38: 193-198.

Ayre K. \& Port G.R. 1996: Carabid beetles recorded feeding on slugs in arable fields using ELISA. In: Henderson I. (ed.): Slug and Snail Pests in Agriculture. BCPC Monographs 66, Farnham, pp. 411-418.

BAILEY S.E.R. \& WedGwood M.A. 1991: Complementary video and acoustic recordings of foraging by two pest species of slugs on non-toxic and molluscicidal baits. Ann. Appl. Biol. 119: $163-176$.

BARKER G.M. 1991: Biology of slugs (Agriolimacidae and Arionidae: Mollusca) in New Zealand hill country pastures. Oecologia 85: 581-595.

Basedow T., Borg $\AA$. \& Scherney F. 1976: Auswirkungen von Insektizidbehandlungen auf die epigäischen Raubarthropoden in Getreidefeldern, insbesondere die Laufkäfer (Coleoptera: Carabidae). Entomol. Exp. Appl. 19: 37-51.

BASEDOW T. 1990: Effects of insecticides and the significance of these effects for agriculture and species number. In: Stock N. (ed.): The Role of Ground Beetles in Ecological and Environmental Studies. Intercept, Andover, pp. 115-125.

Bieri M., Schwweizer H. \& Chrristensen K. 1989: The effect of metaldehyde and methiocarb slug pellets on surface dwelling organisms in grassland. In: Henderson I. (ed.): Slugs and Snails in World Agriculture. BCPC Monographs 41, Farnham, pp. 391-398

Bohan D.A., Bohan A.C., Glen D.M., Symondson W.O.C., Wiltshire C.W. \& Hughes L. 2000: Spatial dynamics of predation by carabid beetles on slugs. J. Anim. Ecol. 69: 367-379.

BURN A.J. 1988: Assessment of the impact of pesticides on invertebrate predation in cereal crops. Aspects Appl. Biol. 17: 279-288.

Campbell C.L. \& Madden L.V. 1990: Introduction to Plant Disease Epidemiology. Wiley, New York, 532 pp.

Chiverton P.A. 1986: Predator density manipulation and its effects on populations of Rhopalosiphum padi (Hom: Aphididae) in spring barley. Ann. Appl. Biol. 109: 49-60.

DENNY M.W. 1989: Invertebrate mucous secretions: functional alternatives to vertebrate paradigms. In: Chantler E. \& Ratcliffe N.A. (eds): Mucus and Related Topics: Symposia of the 
Society of Experimental Biology, No XLIII. Company of Biologists Limited, Cambridge, pp. 337-366.

Edwards C.A., Sunderland K.D. \& George K.S. 1979: Studies on polyphagous predators of cereal aphids. J. Appl. Ecol. 16: 811-823.

FrANK T. 1997: Species diversity of ground beetles (Carabidae) in sown weed strips and adjacent fields. In: Kromp B. \& Meindl P. (eds): Entomol. Res. Org. Agr. Biol. Agric. Hortic. 15: 297-307.

FrANK T. 1998: The role of different slug species in damage to oilseed rape bordering on sown wildflower strips. Ann. Appl. Biol. 133: 483-493.

FriedLI J. \& Frank T. 1998: Reduced applications of metaldehyde pellets for reliable control of the slug pests Arion lusitanicus and Deroceras reticulatum in oilseed rape adjacent to sown wildflower strips. J. Appl. Ecol. 35: 504-513.

GESE K. 1974: Der Einfluss einiger Insektizide bei verschiedenen Anwendungsverfahren auf die Laufkäferfauna (Coleoptera, Carabidae) von Rübenfeldern. Doctoral Thesis, Giessen.

HögGER C. 1995: Schneckenschäden vermeiden. Die Grüne 8 $12-15$.

Kromp B. 1989: Carabid beetle communities (Carabidae: Coleoptera) in biologically, and conventionally farmed agroecosystems. Agric. Ecosyst. Environ. 27: 241-251.

KROMP B. 1999: Carabid beetles in sustainable agriculture: a review on pest control efficacy, cultivation impacts and enhancement. Agric. Ecosyst. Environ. 74: 187-228.

LYS J.-A. \& NENTWIG W. 1992: Augmentation of beneficial arthropods by strip-management 4 . Surface activity, movements and activity density of abundant carabid beetles in a cereal field. Oecologia 92: 373-382.

Lys J.-A. \& NENTWIG W. 1994: Improvement of the overwintering sites for Carabidae, Staphylinidae and Araneae by strip-management in a cereal field. Pedobiologia 38: $238-242$.

Mc Kemey A.R., Symondson W.O.C., Glen D.M. \& Brain P. 2001: Effects of slug size on predation by Pterostichus melanarius (Coleoptera: Carabidae). Biocontrol Sci. Techn. 11: 83-93.

Mesch H. 1996: Was hilft gegen Schnecken im Raps? Top Agrar 8: 52-53.

Murdoch W.W., Chesson J. \& Chesson P.L. 1985: Biological control in theory and practice. Am. Nat. 125: 344-366.

Oberholzer F. \& Frank T. 2003: Predation by the carabid beetles Pterostichus melanarius and Poecilus cupreus on slugs and slug eggs. Biocontrol Sci. Techn. 13: (in press).

PAKARINEN E. 1994: The importance of mucus as a defence against carabid beetles by the slugs Arion fasciatus and Deroceras reticulatum. J. Moll. Stud. 60: 149-155.

Pfiffner L. \& Niggli U. 1996: Effects of bio-dynamic, organic and conventional farming on ground beetles (Col.: Carabidae) and other epigaeic arthropods in winter wheat. Biol. Agric. Hortic. 12: 353-364.
Rollo C.D. \& Wellington W.G. 1979: Intra- and inter-specific agonistic behaviour among terrestrial slugs (Pulmonata: Stylommatophora). Can. J. Zool. 57: 846-855.

SCHERNEY F. 1959: Unsere Laufkäfer, ihre Biologie und wirtschaftiche Bedeutung. Ziemsen, Wittenberg Lutherstadt, $79 \mathrm{pp}$.

South A. 1964: Estimation of slug populations. Ann. Appl. Biol. 53: $251-258$.

SoutH A. 1992: Terrestrial Slugs. Chapman \& Hall, London, $428 \mathrm{pp}$.

SPEISER B. 1997: A new field test for molluscicides in vegetable crops. EPPO Bulletin 27: 235-242.

SPEISER B. 1999: Molluscicidal and slug-repellent properties of anaerobically digested organic matter. Ann. Appl. Biol. 135: 449-455.

Sunderland K.D., Chambers R.J., Stacey D.L. \& Crook N.E. 1985: Invertebrate polyphagous predators and cereal aphids. IOBC Bull. 7: 105-114.

Srmondson W.O.C. 1993: The effects of crop development upon slug distribution and control by Abax parallelepipedus (Coleoptera: Carabidae). Ann. Appl. Biol. 123: 449-457.

Srmondson W.O.C. \& LidDell J.E. 1993: The detection of predation by Abax parallelepipedus and Pterostichus madidus (Coleoptera: Carabidae) on Mollusca using a quantitative ELISA. Bull. Entomol. Res. 83: 641-647.

Symondson W.O.C., Glen D.M., Wiltshire C.W., Langdon C.J. \& LidDELL J.E. 1996: Effects of cultivation techniques and methods of straw disposal on predation by Pterostichus melanarius (Coleoptera: Carabidae) upon slugs (Gastropoda: Pulmonata) in an arable field. J. Appl. Ecol. 33: 741-753.

SYMondson W.O.C.: Coleoptera (Carabidae: Drilidae, Lampyridae and Staphylinidae). In: Barker G.M. (ed.): Natural Enemies of Terrestrial Molluscs. CAB International, Oxford. (in press)

Symondson W.O.C., Glen D.M., Ives A.R., Langdon C.J. \& WILTShIRE C.W. 2002: Dynamics of the relationship between a generalist predator and slugs over five years. Ecology 83: 137-147.

ThIele H.U. 1977: Carabid Beetles in their Environments. Springer, Berlin, $369 \mathrm{pp}$.

TOD M.E. 1973: Notes on beetle predators of molluscs. Entomologist 106: 196-201.

Traugoti M. 1998: Larval and adult species composition, phenology and life cycles of carabid beetles (Coleoptera: Carabidae) in an organic potato field. Eur. J. Soil Biol. 34: 189-197.

VAN Dirk T.S. 1996: The influence of environmental factors and food on life cycle, ageing and survival of some carabid beetles. In: Booij C.J.H. \& den Nijs L.J.M.F. (eds): Arthropod Natural Enemies in Arable Land II - Survival, Reproduction and Enhancement. Acta Jutlandica 71: 11-24.

Received February 18, 2002; revised September 10, 2002; accepted September 12, 2002 